\title{
Spatial Patterns of Urban Expansion in Chinese Cities
}

\author{
Jing Yao ${ }^{\mathrm{a}, *}$, Ya Ping Wang ${ }^{\mathrm{a}}$, Xiaoxiang Zhang ${ }^{\mathrm{b}}$ \\ ${ }^{a}$ School of Social and Political Sciences, University of Glasgow, Glasgow G12 8RZ, UK, Jing.Yao@glasgow.ac.uk, \\ YaPing.Wang@glasgow.ac.uk \\ ${ }^{b}$ Department of Geographical Information Science, Hohai University, Nanjing, 210098, \\ China,xiaoxiang@hhu.edu.cn \\ * Corresponding author
}

Keywords: Urban expansion, GIS, Spatial analysis, China

\begin{abstract}
:
China has experienced high rate urbanization in recent years, with urban population increased from 460 to 750 million and the built-up area of metropolis expanded by almost $60 \%$ since 2000 . Urban landscape has been dramatically changed by intensified inner-city development and urban sprawl. In recent years, the changes in urban form has transformed from expansion to restructuring. A good understanding of urban expansion and spatial restructuring as a consequence of urbanization has important policy implications, enhancing the knowledge of spatial variations in urban growth in transitional Chinese cities and assisting with sustainable urban and regional planning.
\end{abstract}

Using the Landsat satellite images from 1995 to 2015, this research explores urban expansion and its spatial patterns in second-tier Chinese cities, taking Tianjin, Hangzhou and Chengdu as examples, which are the leaders in the urbanization in Northern, Eastern and Western China, respectively. The study area includes the city proper in the three case study cities. Figure 1 shows the expansion of urban area in the three cities over the study time period. By visual inspection, it can be observed that the spatial pattern of urban land use growth varies across the three cities. For example, Tianjin has been largely expanding towards the east, particularly the Tianjin Binhai New Area, which has been rapidly developed into a new city core. The city of Chengdu seems having been expanding toward all directions of the surrounding area, integrated with the adjacent towns into a larger urban agglomeration. Further work will focus on quantitative analysis of the spatial patterns of urban expansion using geographical information system (GIS)-based spatial analytics, as well as the association between urban expansion and socioeconomic changes, with a reflection on the role of national/local policies.

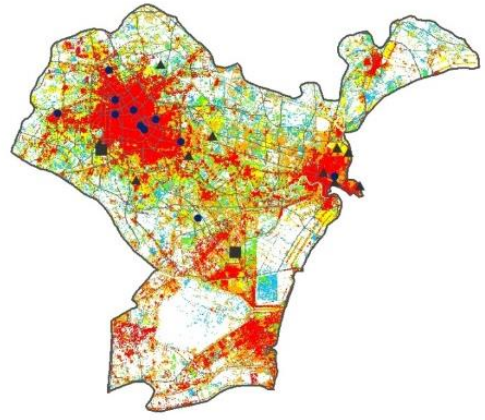

a.Tianjin

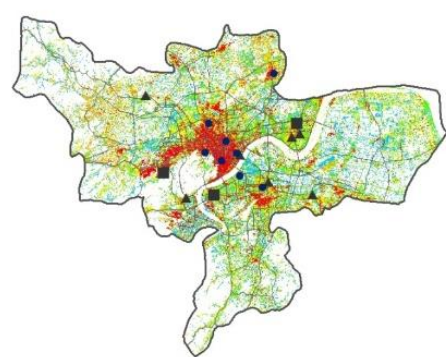

b.Hangzhou

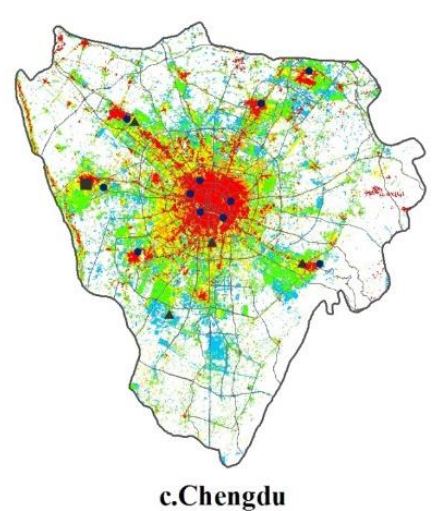

c.Chengdu

Existing urban land in 1995

Main Road

- Main Twon

A Development Zones

- University Town

Urban expansion between 1995 and 2000

Urban expansion between 2000 and 2005

Urban expansion between 2005 and 2010

Urban expansion between 2010 and 2015

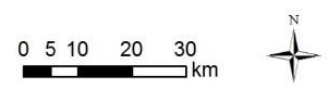

Figure 1. Urban expansion during 1995-2015 in Tianjin, Hangzhou and Chengdu 